\title{
Luminance ratio for extreme shadings
}

Abstract: Luminance ratio $k(-)$ is a photometric magnitude used for daylight calculation metrics. The paper is focused on specification of luminance ratio values and their influence on daylight factor calculations for of extremely shaded outdoor conditions.

Key words: daylighting, daylight factor calculations, luminance of shading obstructions

\section{Introduction}

The luminance ratio $k(-)$ is defined as a ratio of shading obstruction luminance $L_{p}\left(\mathrm{~cd} . \mathrm{m}^{-2}\right)$ and luminance of the sky hemisphere segment. It means there are two luminance ratios [1]: the luminance ratio $k_{\gamma}(-)$ related to luminance $L_{\gamma}$ $\left(\mathrm{cd} . \mathrm{m}^{-2}\right)$ of the sky segment shaded by an obstruction:

(1) $k_{\gamma}=\frac{L_{p}}{L_{\gamma}}$

and luminance ratio $k_{m}(-)$ linked to the mean sky luminance $L_{m}\left(\mathrm{~cd} . \mathrm{m}^{-2}\right)$ :

$$
k_{m}=\frac{L_{p}}{L_{m}}
$$

The relation between the mentioned ratios for conditions of overcast sky (CIE 1:3) [1 - 4] and dark ground is following

$$
k_{\gamma}=\frac{k_{m}}{q}=\frac{7 k_{m}}{3+6 \sin \gamma}
$$

where $\gamma\left({ }^{\circ}\right)$ is elevation angle (from horizon) and $q(-)$ is factor of sky luminance gradation for winter time and overcast sky $(1: 3)$ and dark terrain.

Luminance ratio $k_{y}(-)$ is used for calculation of externally reflected component of daylight factor $D_{e}(\%)$ determined from graphical methods (by Daniljuk or Waldram). The externally reflected component $D_{s}(\%)$ calculation for these graphical methods requires $k_{\gamma}(-)$ value of luminance ratio. Modern computer simulation methods have precisely specified external luminance conditions. The luminance ratio is relatively less important for them. The problem is in the calculation assignments. In many cases daylight studies in the stage of urban planning have not defined colours of neighbouring buildings and shading obstructions.

Values of light reflectance $\rho(-)$ of real surfaces are not available in this stage. Accuracy of luminance distribution for buildings and obstructions in urban planning layouts is for the mentioned conditions relatively limited. For this reason the luminance ratio has importance for daylight evaluations even in the era of computer simulation methods. Czech technical standard [4] recommends value of $k_{\gamma}=0.1$. Shading obstruction luminance is determined as one tenth of the sky luminance - luminance of the sky segment hidden by the shading obstruction. This recommendation is not based on the very accurate value. In common urban planning studies daylighting is considered as sky light component and reflected component and luminance of shading obstructions has relatively little influence on final results of daylighting evaluations. In addition of that it is supposed that value of $k_{\gamma}=0.1$ is on the side of more accurate calculation results. The unification of the input parameters with luminance ratio gives higher measure of reproducibility and reliability of the calculation procedures.

Standards do not exclude different values in cases of their validity documentation and possible application including information about a surface colour. Light reflectance $\rho(-)$ is ratio between reflected luminous flux $\Phi_{r}(\mathrm{Im})$ and total luminous flux affection surfaces $\Phi_{0}(\mathrm{Im})$.

$$
\rho=\frac{\Phi_{r}}{\Phi_{0}}
$$

The light reflectance value depends on colour of the surface. Daylight standard [4] recommends the light reflectance of terrain $\rho_{T}=0.1$ (grass, asphalt pavement). Light reflectance of window glazed areas is considered as $\rho_{W}=0.1$. Light reflectance of the non-transparent parts of the facade needs to be carefully considered. All external surfaces degrade during the building life cycle because of weathering and dust. The surface degradation causes reduction of light reflectance. It is possible to evaluate white façade reflectance of value $\rho_{F}=0.7$ and less considering the façade degradation process. Daylight calculations require mean values of light reflectance $\rho_{m}(-)$. This value depends on percentage of window glazed area in the façade, see Fig. 1.

It is legible that all facades with window percentage more than $70 \%$ should be considered as dark surfaces with the mean light reflectance $\rho_{m}<0.3$ and also nontransparent parts of facades with surface reflectance $\rho_{F}<0.3$. Façade with window percentage $50 \%$ is on the limit between light and dark surface with light reflectance $\rho_{F}=0.5$.

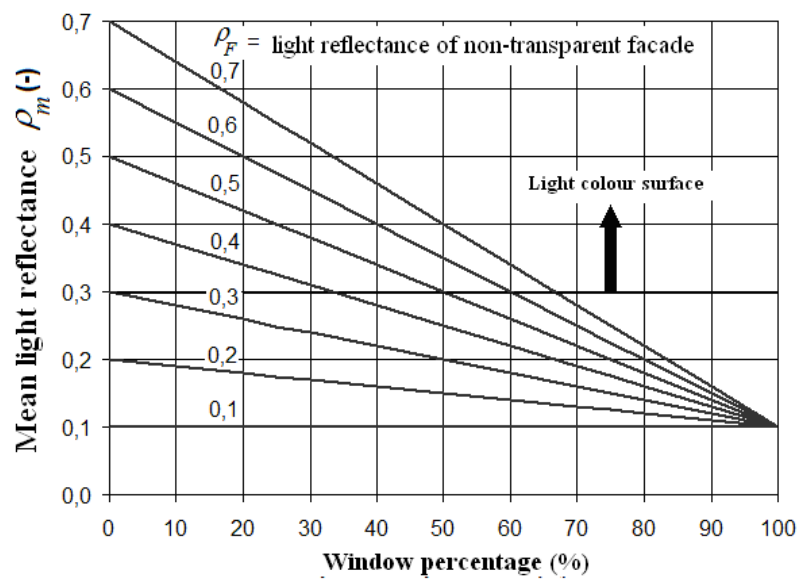

Fig. 1: Mean light reflectance, facade colour and glazing \%

\section{Aim of the study}

Requirements for daylighting of work places have been significantly limited for last decade in the Czech Republic 
and in some European countries. It is a common practice to design work places with integral lighting [3]. Daylight component for the integral lighting is reduced for one third compared to the daylighting demands [4]. Visual activity as reading and writing are adequate to classification IV according to the standard limits for daylighting in buildings [4]. The standard requirement is $D=1.5 \%$ [4], while the minimal daylight component for the integral lighting is $D=0.5 \%$ [3]. It means that indoor work places with very small and shaded windows are acceptable from integral lighting point of view.

The direct sky component of daylighting is neglected in case of extreme shadings but on the other hand light reflectance is very important. Lack of sky component in narrow streets and courtyards causes reduction of neighbouring facades luminance. Colour of the façade plays also important role for daylighting. Many modern buildings are unfortunately design in dark facings colours. Dark colours significantly reduce façade luminance (Fig. 2).

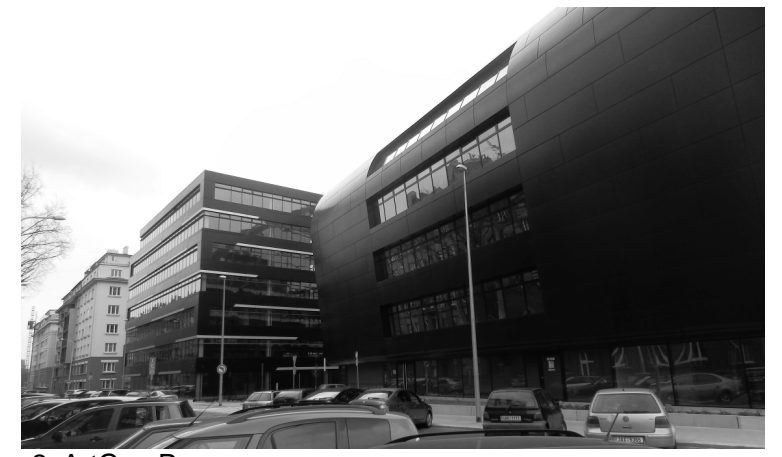

Fig. 2: ArtGen Prague

The question is whether the luminance ratio $k_{\gamma}=0.1$ can be considered as a relevant value for daylight evaluations in such unfavourable daylight conditions.

\section{Model luminance ratio calculation method}

The answer to the above mentioned question is presented in the following results of the model evaluation and simulations in software SVĚTLO+ [1], [5]. Calculations were completed for direct components of daylight factors sky component $D_{s}(\%)$ and externally reflected component $D_{e}(\%)$ were calculated in individual points of a façade wall. The internally reflected component $D_{i}(\%)$ was calculated on the Radiosity method [1] calculation principle. The software simulates luminance ratios $k_{m}$ (-) for set of points on the shading obstructions and facades. The calculation was carried out for two models of urban planning situations: model $\mathbf{U}=$ very long straight street of width $10 \mathrm{~m}$, model $\mathbf{D}=$ squared courtyard of area $10 \mathrm{~m} \times 10 \mathrm{~m}$. Both of the models were simulated for shading angles $\varepsilon=30,35,40,45,50,55$ and $60^{\circ}$. Influence of the shading angle $\varepsilon\left({ }^{\circ}\right)$ is obvious from Fig. 3 .

Light reflectance of terrain was selected $\rho_{T}=0.1$. Mean light reflectance of all facades facing to the street or to the courtyard $\rho_{m}(-)$ was specified in variations. It was determined from window light reflectance $\rho_{W}=0.1$ and light reflectance of non-transparent part of the façade $\rho_{F}$ from 0.5 (light grey) to 0.7 (white). The mean value of the façade light reflectance is $\rho_{m}=0.1 ; 0.2 ; 0.3 ; 0.4$ and 0.5 in dependence on colour and window percentage in the façade. An example of luminance ratio $k_{m}(\%)$ of a façade facing to the courtyard is shown in Fig. 4, simulated in software SVĚTLO+ [1], [5].

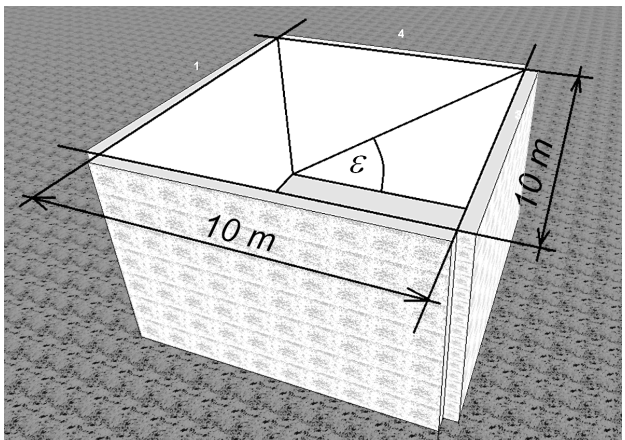

Fig. 3: Shading angle $\varepsilon\left(^{\circ}\right)$, for the courtyard $10 \mathrm{~m} \times 10 \mathrm{~m}$

Correction of luminance ratio $k_{m}(-)$ for the value of $k_{\gamma}(-)$ was provided according to equation ( 3 ), where angle between horizontal working plane in the room and the light rays direction is $\gamma=20^{\circ}$. Calculated values of $k_{\gamma}(-)$ of the façade in the ground floor level are shown in Fig. 5, in dependence on shading angle $\varepsilon\left({ }^{\circ}\right)$ and mean light reflectance $\rho_{m}(-)$.

Simulation results for model $\mathbf{U}$ - street $10 \mathrm{~m}$ and for model D - courtyard $10 \mathrm{~m} \times 10 \mathrm{~m}$ are compared in Figure 5 for values of luminance ratio $k_{y}(-)$ in the middle of the façade and in its corner. Chain line depicts value $k_{\gamma}=$ 0.1 (respectively $k_{y}=0.05$ ) that is recommended by the technical standard for daylighting in buildings [4].

Model $\mathbf{U}$ - street $10 \mathrm{~m}$, has calculated values of $k_{\gamma}(-)$ for the real values of mean light reflectance $\rho_{m}=0.4$ to 0.5 in compliance with the standard recommendation $k_{\gamma}=0.1$, it means that the calculation inputs are correct and they are not overestimated. Problem was with calculations for the lower values of light reflectance (big windows, dark facade). Value of $k_{y}<0.1$ was calculated for $\rho_{m}=0.3$ and for shadings from angle $\varepsilon=45^{\circ}$.

Finally the lowest values of $\rho_{m}(-)$ gave the luminance ratio $k_{\gamma}<0.1$ even for shading angle $\varepsilon=30^{\circ}$. Despite of the above mentioned results the standard recommendation for luminance ratio $k_{\gamma}=0.1$ is adequate for daylight evaluations in case of streets with building façades of light colours and for shading angle $\varepsilon=60^{\circ}$.

Simulation model D - courtyard gives rather adverse values of the luminance ratio. Values of $k_{y}<0.1$ were determined for light colour façade surfaces and shadings from 40 to $45^{\circ}$. It would be reasonable to select value of $k_{\gamma}=0.05$ from shading angles $\varepsilon=40^{\circ}$ and more for correct results, in case of the courtyard model with light colour facades. Recommendation for dark façades $\left(\rho_{m}<0.3\right)$ is for reduction of the luminance ratio, even for lower shading angles. For dark facades and for shadings $\varepsilon>40^{\circ}$ the luminance ratio is recommended to be minimized, or example $k_{\gamma}=0.02$.

Values of luminance ratio for model evaluations have surprisingly relatively high difference between model of $\mathbf{U}$ street and model D - courtyard. The courtyard is surrounded by building facades. The courtyard model has lower luminance distribution compared to the street model of the same shading angle $\varepsilon\left({ }^{\circ}\right)$. It seems that the lower values of luminance ratio than the standard recommended value would be positive for the courtyard daylight simulation accuracy. 


\begin{tabular}{|c|c|c|c|c|c|c|c|c|c|c|c|c|c|c|c|c|c|}
\hline & & & & & & 12.94 & & & & 12.94 & 12.93 & 12.93 & 12.92 & 12.89 & 12.81 & 12.60 & 11.62 \\
\hline 9.36 & 10.87 & 11.60 & 11.93 & 12.10 & 12.20 & 12.25 & 12.28 & 12.29 & 12.29 & 12.28 & 12.25 & 12.20 & 12.10 & 11.93 & 11.59 & 10.85 & 9.31 \\
\hline 8.45 & 9.64 & 10.50 & 11.00 & 11.30 & 11.47 & 11.58 & 11.64 & 11.66 & 11.66 & 11.63 & 11.57 & 11.47 & 11.29 & 11.00 & 10.49 & 9.62 & 8.42 \\
\hline 7.86 & 8.77 & 9.57 & 10.12 & 10.48 & 10.72 & 10.87 & 10.95 & 10.99 & 10.99 & 10.95 & 10.86 & 10.71 & 10.48 & 10.11 & 9.56 & 8.75 & 7.84 \\
\hline 7.38 & 8.08 & 8.79 & 9.33 & 9.71 & 9.97 & 10.15 & 10.25 & 10.30 & 10.30 & 10.25 & 10.14 & 9.97 & 9.70 & 9.32 & 8.78 & 8.07 & 7.36 \\
\hline 6.95 & 7.50 & 8.12 & 8.61 & 8.98 & 9.25 & 9.44 & 9.55 & 9.61 & 9.61 & 9.55 & 9.44 & 9.25 & 8.98 & 8.60 & 8.11 & 7.49 & 6.93 \\
\hline 6.54 & 6.99 & 7.52 & 7.96 & 8.31 & 8.57 & 8.76 & 8.87 & 8.93 & 8.93 & 8.87 & 8.75 & 8.57 & 8.30 & 7.95 & 7.51 & 6.98 & 6.53 \\
\hline 6.15 & 6.52 & 6.97 & 7.37 & 7.68 & 7.93 & 8.11 & 8.22 & 8.28 & 8.28 & 8.22 & 8.11 & 7.93 & 7.68 & 7.36 & 6.97 & 6.51 & 6.14 \\
\hline 5.78 & 6.08 & 6.48 & 6.82 & 7.11 & 7.33 & 7.50 & 7.61 & 7.66 & 7.66 & 7.61 & 7.50 & 7.33 & 7.10 & 6.82 & 6.47 & 6.07 & 5.77 \\
\hline 5.43 & 5.67 & 6.01 & 6.32 & 6.58 & 6.78 & 6.93 & 7.03 & 7.08 & 7.08 & 7.03 & 6.93 & 6.78 & 6.57 & 6.31 & 6.01 & 5.66 & 5.42 \\
\hline 5.08 & 5.28 & 5.59 & 5.85 & 6.08 & 6.27 & 6.40 & 6.50 & 6.54 & 6.54 & 6.50 & 6.40 & 6.26 & 6.08 & 5.85 & 5.58 & 5.28 & 5.08 \\
\hline 4.75 & 4.92 & 5.18 & 5.42 & 5.63 & 5.79 & 5.92 & 6.00 & 6.04 & 6.04 & 6.00 & 5.92 & 5.79 & 5.62 & 5.42 & 5.18 & 4.91 & 4.75 \\
\hline 4.44 & 4.57 & 4.81 & 5.02 & 5.20 & 5.35 & 5.47 & 5.54 & 5.58 & 5.58 & 5.54 & 5.47 & 5.35 & 5.20 & 5.02 & 4.80 & 4.57 & 4.44 \\
\hline 4.14 & 4.25 & 4.45 & 4.65 & 4.81 & 4.95 & 5.05 & 5.12 & 5.16 & 5.16 & 5.12 & 5.05 & 4.95 & 4.81 & 4.64 & 4.45 & 4.24 & 4.13 \\
\hline 3.90 & 3.98 & 4. 18 & 4.37 & 4.53 & 4.65 & 4.75 & 4.82 & 4.85 & 4.85 & 4.82 & 4.75 & 4.65 & 4.52 & 4.37 & 4.18 & 3.98 & 3.90 \\
\hline
\end{tabular}

Fig. 4: View of the inner courtyard facade (for model $\varepsilon=40^{\circ}$ and $\rho=0.3$ ) with the calculated values of average luminance ratio $k_{m}(\%)$.

Model U - street, $10 \mathrm{~m}$

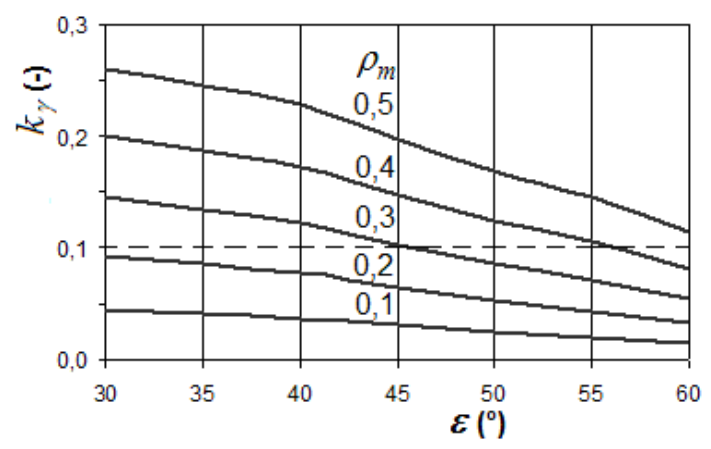

Model D - courtyard $10 \mathrm{~m} \times 10 \mathrm{~m}$, in the middle
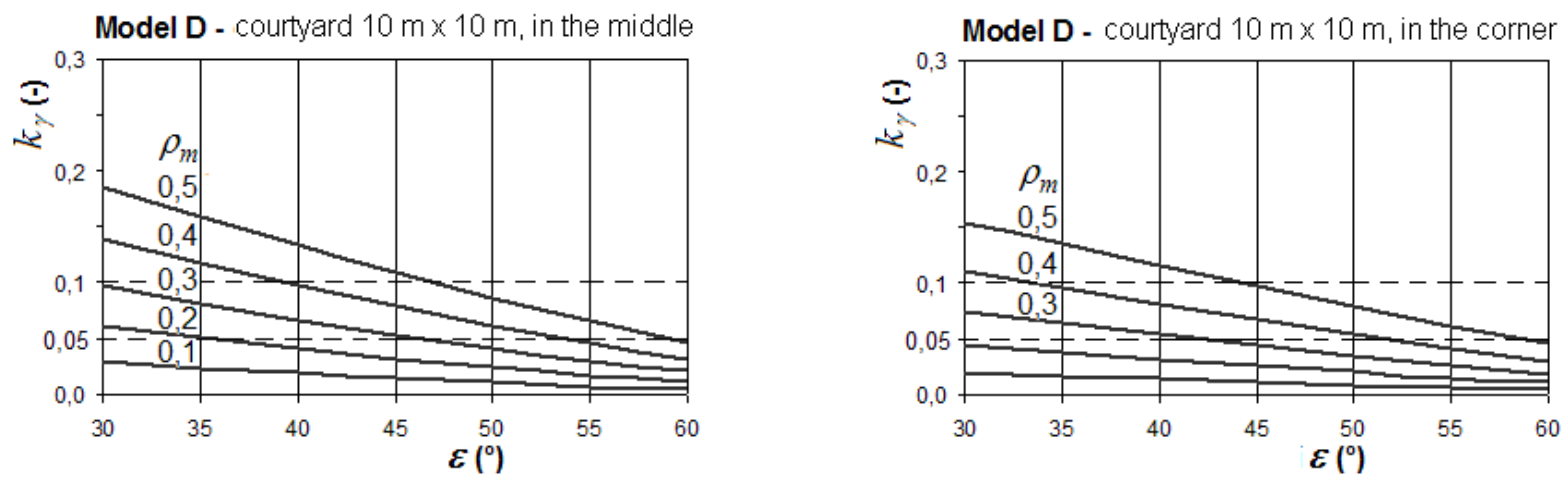

Fig. 5: Diagrams of calculated values $k_{\gamma}(-)$ in dependence on shading angle $\varepsilon\left(^{\circ}\right)$ and mean light reflectance $\rho_{m}(-)$

\section{Luminance measurement}

Luminance measurements were carried for a minimised model of a courtyard completed of a cartoon box of dimensions $575 \mathrm{~mm} \times 380 \mathrm{~mm} \times 330 \mathrm{~mm}$. Different dimensions of the paper model compared to the simulations can be used because the luminance ratio is calculated as the luminance ratio. The box was lined with a paper of determined light reflectance. Measurements were carried out under overcast sky. Outdoor conditions were controlled in accordance with standard ČSN 36 0011-2 [2]. Results of measurements are in a good compliance with simulation outputs run in software SVËTLO+. 
luminance measurement points

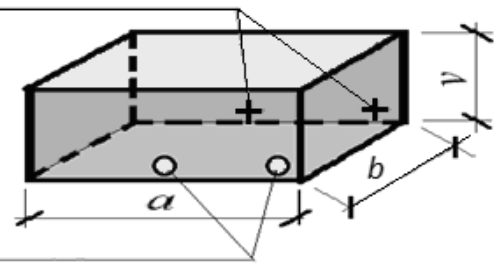

openings for measurement

Fig. 6: Scheme of the model for luminance measurements

\section{Daylight factor calculation}

Values of luminance ratio were lower than the standard recommendations of $k_{y}=0.1$, for extreme shadings in model D - courtyard. The following study was focused on computer simulations and evaluation of luminance ratio influence on daylight factor in a model room. The room is located on the found floor in the middle of the courtyard facing façade. The room floor area is $9.1 \mathrm{~m}$ $\times 4.5 \mathrm{~m}$ and clearance height $3.0 \mathrm{~m}$. Three windows of dimensions $2.5 \mathrm{~m} \times 2.0 \mathrm{~m}$ (window sill $0.8 \mathrm{~m}$ ) are oriented to the courtyard, Figure 7 . Window glass unit light transmittance is $\tau_{s}=0.846$; non-transparent framing represents $20 \%$ of the window area - frame correction $\tau_{k}=0.80$; external dirt factor $\tau_{z e}=0.90$; internal dirt factor $\tau_{z i}=0.95$. Light reflectance of internal surfaces: floor 0.7 ; walls 0.5 and floor 0.3 .

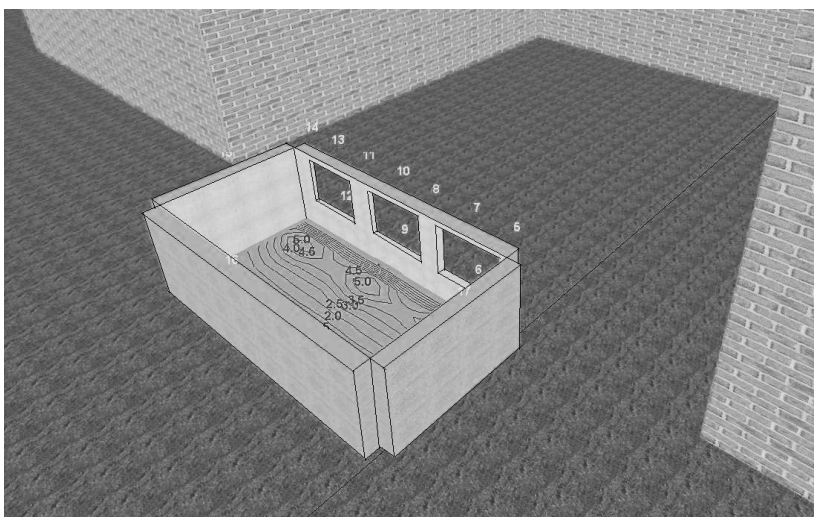

Fig. 7: Scheme of the model room (simulated in SVÉTLO+)

The SVĚTLO+ simulation results of daylight factor $D(\%)$ distribution on a horizontal work plane in the position $0.85 \mathrm{~m}$ over the room floor is shown in Figure 8. Results are presented in graphical form as isolines of values $D=1.5 \%$ and $D=0.5 \%$ and in variations for different values in range $0.2 ; 0.3 ; 0.4$ and 0.5 of mean light reflectance $\rho_{m}(-)$ of facades facing to the courtyard. The chain isoline represents curves determined for $k_{\gamma}=0.1$ - the standard value. The curves are presented in three schemes for the shading angle $\varepsilon=30^{\circ}, 45^{\circ}$ and $60^{\circ}$, Figure 8 .

\section{Discussion}

Shading angle $\varepsilon=30^{\circ}$ - daylight level of $D>1.5 \%$ is convenient for about $a$ half of the room. The area of the functionally limited part of the room close to windows does not depend on light reflectance of the façade $\rho_{m}(-)$. It is caused in the consequence that the daylight level of $D>1.5 \%$ is mainly influence by the sky component. Isolines of daylight factor of $D=0.5 \%$ are practically not visible in the room plan (only in corners). The room can be illuminated due to integral lighting in the whole room area. It is possible to conclude that the luminance ratio $k_{\gamma}=0.1$ is applicable for shading angle $\varepsilon=30^{\circ}$ for daylight and integral light evaluation.

Shading angle $\varepsilon=45^{\circ}$ has for a functionally limited space with $D>1.5 \%$ smaller daylight area but daylight level is also not very influenced by the courtyard façade reflectance. In contrary daylighting in the room part with isoline of $D=0.5 \%$ depends on light reflectance $\rho_{m}(-)$. Luminance ratio $k_{y}=0.1$ corresponds with light reflectance $\rho_{m}=0.5$ (see the chain line). The value of $k_{\gamma}=0.1$ is not on the side of correct results for lower reflectance and this value causes overestimation of the simulation outputs.

Shading angle $\varepsilon=60^{\circ}$ : the problem noted in the previous paragraph is more important for higher shading angle. Value of $k_{y}=0.1$ gives overestimation of the simulation results also for daylight factor $D>1.5 \%$. The daylight area is very small in this case. The room has not convenient daylighting even in the position of windows The room limited area with daylight factor $D>0.5 \%$ is overestimated for mean light reflectance $\rho_{m}=0.5$.

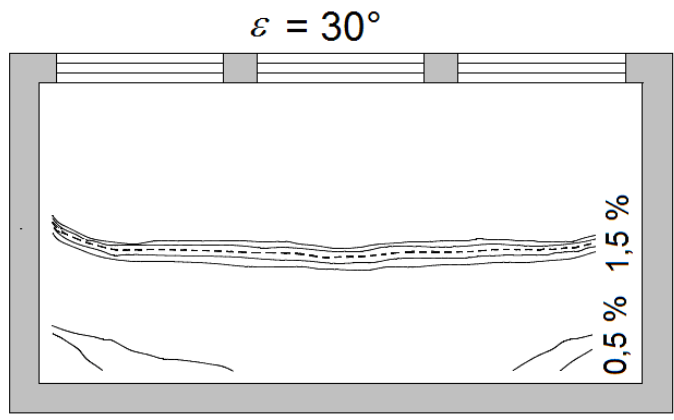

$\varepsilon=45^{\circ}$

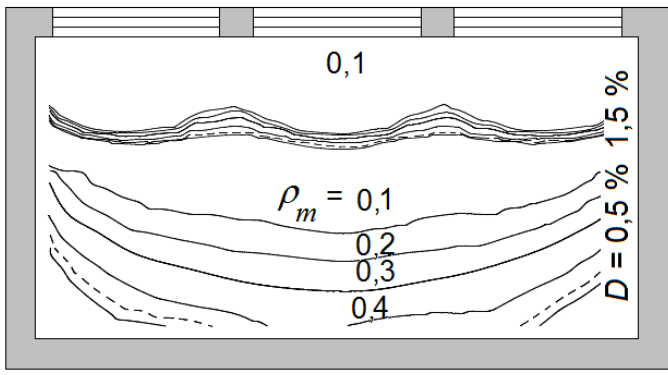

$$
\varepsilon=60^{\circ}
$$

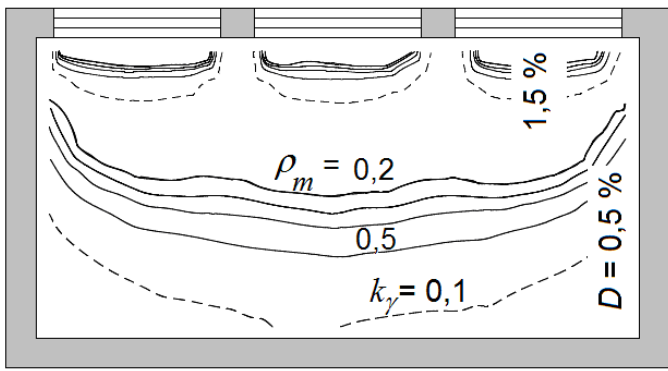

Fig. 8: Daylight factor isolines

\section{Conclusion}

Calculations of luminance ratio $k_{\gamma}(-)$ were completed for shaded building facades for the model of very long street and model of the square plan courtyard. Daylight factor $D(\%)$ calculation for the model room was simulated in SVËTLO+. The evaluation was focused on verification of standard value $k_{y}=0.1$ whether this value is applicable with sufficient accuracy for extremely shading conditions. 
There are some conclusions emerged from the evaluations:

1) Model $\mathbf{U}$ - long straight street: the application of luminance ratio $k_{\gamma}=0.1$ was found correct and adequate for light colours of shading buildings and for relatively high shading angles.

2) Model D - courtyard: the value of luminance ratio $k_{y}=0.1$ was found to be only adequate for lower shading angles (up to $\max \varepsilon=30^{\circ}$ ). The value of $k_{\gamma}=0.1$ is not convenient for higher shading angles and dark facades and shading obstructions. It practically means that this value is not convenient for accuracy of daylighting and especially integral light calculations.

3) Mean light reflectance $\rho_{m}(-)$ of shading obstructions has minimal influence on the daylight factor isoline of $D=1.5 \%$. It is caused due to the sky component dominant influence on the room daylight factor distribution.

4) For extreme shadings $\left(\varepsilon>40^{\circ}\right)$ the influence of light reflectance $\rho_{m}(-)$ of facades and shading obstructions on daylight factor of $D=0.5 \%$ is significant and for common cases the value of $k_{\gamma}=0.1$ has influence on overestimated results. It means the results are not on the side of the calculation accuracy.

Results of the presented evaluations confirmed that the value of standard recommendation for the luminance ratio of shading obstructions $k_{\gamma}=0.1$ is not based on the correct accuracy data for extreme shading conditions. The following research focused on the detail evaluations of luminance ratio would be useful for a possible specification of a corrected value for extremely shaded conditions into technical standards.

\section{Acknowledgement}

This paper has been worked out under the European Union - project OP VaVpl No. CZ.1.05/2.1.00/03.0091 University Centre for Energy Efficient Buildings, under the project no. LO1408 "AdMaS UP - Advanced Materials, Structures and Technologies", supported by Ministry of Education, Youth and Sports under the "National Sustainability Programme I" and under the project TE02000077, Smart Regions-Buildings and Settlements Information Modelling, Technology and Infrastructure for Sustainable Development.

\section{REFERENCES}

[1] Kaňka, J: Vybrané stati ze stavební světelné techniky. CTU in Prague, 2014, p. 74-78, Czech Republic, ISBN 978-80-01-05468-0

[2] ČSN 36 0011-2 Lighting measurements in areas - Part 2: Measurement of daylighting. Prague: ÚNMZ (2014), Czech Republic (in Czech original: ČSN 36 0011-2 Měřeni osvětlení prostorù - Část 2: Měření denního osvětlení)

[3] ČSN 360020 Integral Lighting - Basic Requirement. Prague: ÚNMZ (2015), Czech Republic (in Czech original: ĆSN 360020 Sdružené osvětlení)

[4] ČSN 73 0580-1 Daylighting in buildings - Part 1: Basic requirements. Prague: CNI (2007), Amendment Z1 (2011), Czech Republic (in Czech original: ČSN 73 0580-1 Denni osvětlení budov - Část 1: Základní požadavky)

[5] JpSoft s.r.o. SVÉTLO+. Software for daylighting and for insolation of buildings, Version 1.32 profi. Information on the www.svetloplus.cz

Authors: doc. Ing. Jan Kaňka, Ph.D., Faculty of Civil Engineering, CTU in Prague, Thakurova 7, Prague 6, Czech Republic, e-mail:kanka@fsv.cvut.cz 